\title{
How Algerian sociology turned his back to applied researches?
}

\author{
Faradji Mohamed Akli \\ Professor of sociology, faculty of social sciences and humanities University of Bejaia ,Algeria
}

(Received 22 October 2018, accepted 21 April 2019)

https://doi.org/10.36224/ijes.120202

\begin{abstract}
According to the basic definitions, sociology is a science that always seeks to explain the hidden meaning of social phenomena. This orientation is versed to unveil the facts of social reality. So the role of the sociologists is to objectively explain this reality, this is also a scientific researcher completed by theoretical concepts and empirical methodology. The sense of curiosity for him is a weapon of the dice covered research.As it is also the scientist who uses legitimate tools of clarification and objective explanation of observable facts by questionable results as a scientific researcher filled and critically.

Our communication tries to analyze Algerian sociology according to major transformations of society and respectful mutations experienced by the society in recent year's evolution. In this way, our main interrogation attempt to verify the initial hypothesis which consists in saying that the academic discourse in sociology in Algeria is far from the concerns of society, or rather knowledge away from the training system of the same discipline.
\end{abstract}

Keywords: sociology, academic discourse, training system.

\section{Introduction}

It is quite clear that sociology in Algeria has experienced a significant quantitative leap, counting up to date, 38 departments in universities across the country, hosting thousands of students per year Nevertheless, some Algerian researchers suggest that the Debate around this quantitative evolution must be accompanied by a deep reflection on the evolution of the quality of the sociological discourse in Algeria. As for the others, they think that the social exclusion of the social sciences by the State may lead to a flexible delay in the discipline, while some analyzes confirm that the social sciences must necessarily participate in the advent of societies.

But the important question is also related with the real impact of this quantitative evolution in front of social change ;in this context, it is easy to observe that the sociological orientation in deferent academicals fields are not adapted to the deferent preoccupation of society .

This is why it's very necessary to explain how the Algerian sociology turned his back to applied studies?

\section{Historical origin of the discipline with colonial expedition}

We have identified some exploratory studies in Algeria, what we commonly call colonial sociology, such as those conducted by military administration, head of the Arab section during the colonial period, who tried to present an image of customs, rituals and the habits of the natives, whose main objective is always to explore the Algerian culture, traditions in order to vacillate the military operations, this is the basic orientation of colonial purposes. 
According to some academicals studies of sociologists, the assisted existence of sociology in Algeria accompanies the colonial strategy of the French administration. Which explains, that the integration of sociology in Algerian history is practically related with the military, colonial policy carried out by the French administration in this specifically time.

\section{The weight of ideological and political orientations}

The application of the first reforms in higher education by the change of administrative status of the teaching of sociology like a social discipline with the creation of the first department related to the Institute of Social Sciences. During this period the Arabic language (1972) has gradually been introduced in the teaching of sociology and has continued until the total Arabization of the social sciences and other humanities disciplines which started in 1980.

This period is characterized by his populist and ideological discourse, these reforms of higher education, notes Djamel Guerrid and the all orientations are inspired by the recommendations of the American research office Arthur D. Little (1971) who realized a extensive study at the request of the Ministry of Higher Education of this time.

In this period, the teaching of sociology is at the same time faced with ideological pressure in the global sense, and a cleavage of methodological and epistemological order. Indeed, on the ideological side, most Algerian sociologists fiercely defended Marxism, as a great left current that was divided into several branches: classical Marxists, Orthodox, "maos", "stalls" of the Althusserians by defending the socialist ideology, where the ideology of the system in place .

This role of encouraging the administration's desire is also versed to marginalize and devalue the social sciences, seeking to promote and encourage a militant or apologetic sociology produced by organic intellectuals whose task is to construct ideological discourses justifying or obscuring the mechanisms of political domination.

These organic intellectuals have sometimes drawn from vulgar Marxism in order to accredit the revolutionary image of the regime, sometimes in the Salafist discourse to attest to its authenticity. The militant sociology of the 1970s distinguished itself in the diffusion of inhibitory myths that were difficult to challenge at the university, on pain of being blacklisted. And that the debate around the criticism of this ideology was strictly forbidden, which we reach the exclusion of a teacher if he tries to criticize socialism as an alternative or system of political and economic governance, there was even a 1985 statesponsored regulation of the civil service, inspired by the party, allowing for the prosecution of teachers who do not respect the policy options of the regime.

It was a period characterized by censorship, the ban on publications that expose a negative balance sheet or a critical reading of the system in place. For this purpose, nobody can speak about critical sociology, but rather about sociology of state or political system.

However, different themes have been studied and especially focusing on the contribution of socialism to the economical development, such as socialist culture, socialist management of enterprises, social demography, the working class, industry, etc. On the epistemological side, the division between Arabic and French-speaking is clearly emerging. In this same time we are assisting to the departure of French cooperating teachers and the replacement by teachers from Arab countries, such as Egypt., Iraq, Syria. 


\section{The problem of valorization toward the practical studies}

Among the problems which affect negatively the evolution of the social sciences, the question of political and material valorization is the most very important problem which limits the progress of this academicals fields in the third world countries and especially in Algerian society.

The political of marginalization reserved to the social sciences is a period characterized by a significant quantitative leap in terms of enrolled students and existing teacher-researchers, and even the considerable number of departments created throughout the national territory, of which we let us count until today 30 Departments of Sociology. This period is the most important compared to the previous ones, it is the specific conjuncture characterized by political events of October 1988, this is also the year of stopping of electoral process .In the same time the submerged period of the country caused by a decade of scientific sterility, and the appearance Indeed, it was during this period that the institutionalization of sociology was made, moreover, the teaching is entirely provided in Arabic language except the University of Bejaia where the teaching is taught in French. Recall that at this time, the semester modular system is replaced by the annual system and the number of modules is reduced to 28 .

They are spread over the eight semesters of the license, at the end of the course, the student must produce a dissertation that he will present before a jury of university teaching, but things will rather degrade with the imposed generalization of the LMD system, where the license is no longer required.

\section{Difficulties of empirical studies}

There are many complexes and difficulties that limit the development of an applied sociology in Algeria and the access to the field of study becomes a very difficult task and this is due to several social and mental considerations.

In general, there are objective reasons due to the academic training system that does not encourage field surveys or practical research and, on the other hand, students' choices are generally oriented towards easy and repetitive theoretical themes that do not cost time and material resources.

On the other hand, there is a complete absence of social and economic demand which does not positively judge the role of the social sciences and does not recognize the scientific value of these disciplines. This situation of social and material difficulties of practical studies is approach the question of the absence of the economic demand related to the economic enterprises, it is also the same statement observed compared to the public institutions.

In the other hand we can clearly say that the public institutions which never solicit the scientific task of academicals or the sociologists is in the same time the same institutions who are spending big budget limited to teaching functions ; this is a great contradiction with the academicals missions of this same institutions .

\section{Conclusion}

We believe that the important thing in this study is to be able to give a faithful archive for the history of sociology in Algeria, facilitating bibliographic research for academics anxious to understand sociological practice in Algeria.

Sociology in this country remains a discipline both old and nascent, a cultural production that emerged in a specific historical context; characterized by multiple changes 
in the social order, and a multidimensional dynamic beyond the academic scope of the discipline itself.

This is not a luxury science, but quite obvious, but rather a synthesis of the intelligentsia of man. It is deeply inscribed in history, and in tradition.

Thinking about a critical sociology in Algeria seems to be a necessity for every researcher anxious to understand the mechanisms of production and reproduction of this science, but also to understand the society that is the subject of this discipline that has disturbed in the past and that will disturb again in the future.

\section{References}

1. Abdelghani Megherbi, culture et personnalité algérienne de Massinissa à nos jours, OPU, Alger ,1986

2. ALDAFATIR, les cahiers algériens de sociologie, revue des recherches éditée par le département de sociologie d'Alger NO 1, ALGER 2000

3. Ali EL KENZ, l'Algérie et la modernité, CODESRIA, Dakar ,1989

4. Gérard Leclerc, Anthropologie et colonialisme, fayard, paris, 1972

5. M. Boutefnouchet, Aperçu historique de l'enseignement de la sociologie à l'université d'Alger ,sociologie no 4 ,Alger ,1991

6. M'Hamed Boukhebza, Ruptures et transformations sociales en Algérie, OPU, Alger ,1989

7. Mohamed Akli FARADJI, la recherche sociologique et le discours politique en Algérie, synthèse des mémoires de licence en sociologie, université d'Alger ,1994

8. P. Lucas et J.C Vatin, l'Algérie des anthropologues, François Maspero, paris ,1982

9. Wadi Bouzar, la culture en question, SNED, Alger ,1982 